\title{
Residential building and occupant vulnerability to pyroclastic density currents in explosive eruptions
}

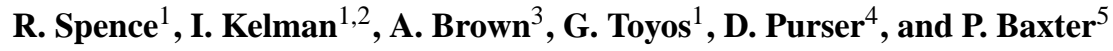 \\ ${ }^{1}$ Department of Architecture, University of Cambridge, UK \\ ${ }^{2}$ National Center for Atmospheric Research (supported by the National Science Foundation), USA \\ ${ }^{3}$ Cambridge Architectural Research, Ltd, UK \\ ${ }^{4}$ Hartford Environmental Research, UK \\ ${ }^{5}$ Institute of Public Health, University of Cambridge, UK
}

Received: 28 November 2006 - Revised: 19 February 2007 - Accepted: 19 February 2007 - Published: 12 March 2007

\begin{abstract}
A major hazard during the eruption of explosive volcanoes is the formation of pyroclastic density currents (PDCs). Casualties and physical building damage from PDCs are caused by the temperature, pressure, and particle load of the flow. This paper examines the vulnerability of buildings and occupants to the forces imposed by PDCs along with associated infiltration of PDC particle and gas mixtures into an intact building. New studies are presented of building and occupant vulnerability with respect to temperature, pressure, and ash concentration. Initial mitigation recommendations are provided.
\end{abstract}

\section{Impacts of pyroclastic density currents on buildings and people}

\subsection{Introduction}

Explosive volcanic eruptions can be accompanied by pyroclastic density currents (PDCs) which are clouds of erupted particles and gases capable of flowing down volcano slopes at high speeds. They pose severe hazards to settlements and their inhabitants from their high temperature and their lateral dynamic pressure loading due to their density and velocity. Several historical examples exist of disasters caused by PDCs, such as St. Pierre Martinique in 1902, where over 28000 people were killed and at Mt. Lamington, Papua New Guinea, in 1953, when nearly 3000 people were killed. The mechanisms which govern the destructiveness of PDCs and the vulnerability of buildings and people to their impacts have, until now, been rarely examined systematically.

This paper contributes to ongoing work in this area by investigating the vulnerability of buildings and occupants to the impacts of PDCs, including the hazard from the infil-

Correspondence to: R. J. S. Spence

(robin@carltd.com) tration of their hot air and gas mixture into intact buildings. New studies are presented which could be applied to any location threatened by PDCs, although the buildings on which the material here is based were mainly in locations at four explosive volcanoes in Europe. The details of the building surveys we undertook are outlined in Spence et al. (2005a, b).

\subsection{Literature overview}

The previous literature on this topic falls into three main categories: the main causes of death, the causes of building damage, and the first attempts at modelling loss of life and building damage from pyroclastic flows. This section summarises that work.

In an overview of deaths in volcanic eruptions since AD 1 , Simkin et al. (2001) showed that PDCs have been the most important single cause of death with $28 \%$ of all fatalities being attributed to them. However, PDCs are second to tephra fallout in terms of the number of volcanic eruptions with fatalities because ash falls occur in almost all eruptions and can inflict damage to buildings and their occupants over more extensive areas than the much more lethal PDCs. Blong (1984) and Baxter (1990) provided information on the occurrence and mechanisms of death in PDCs from a sparse literature that relies on descriptive accounts of a few major events with only one city destroyed by a PDC (St. Pierre, Martinique, in 1902).

Autopsies have been rare after volcanic eruptions, but were performed at Mount St Helens in 1980 (Eisele et al., 1981). This detailed study, based on 25 victims, indicated how the cause of death was related to the distance from the vent as the velocity, density and temperature of the PDC fell over the course of a run-out that extended as far as $28 \mathrm{~km}$. Thus, instant death due to the high temperature (over $400^{\circ} \mathrm{C}$ ), and complete occlusion of the airways by ash, was found in bodies which had not been buried or obliterated in the direct flow area. Asphyxia, severe thermal injuries to the skin,

Published by Copernicus GmbH on behalf of the European Geosciences Union. 
inhalation injury to the lungs and trauma from being struck by missiles and falling trees were fates further away. The 58 deaths all occurred out in the open in a wilderness area, and evidence from other eruptions (see Blong, 1984) has been consistent in showing that survival outdoors is only possible in the periphery of a PDC when it has been well diluted by air and has almost stopped moving. For example, extreme heat was the overwhelming cause of death in victims sheltering in the beach chambers at Herculaneum in the AD 79 eruption of Vesuvius (Mastrolorenzo et al., 2001).

However, Baxter et al. (2005) have summarised the sparse evidence for human survival inside buildings and studied the impacts of PDCs during the eruption of the Soufriere Hills volcano on Montserrat to provide a detailed account of building vulnerability to PDCs, including the implications for the survival of occupants in future eruptions if warning and advanced evacuation fails. This work formed the conceptual basis for understanding the likely behaviour of the more dilute PDC and the causes of building vulnerability in a densely urbanised area, such as around Vesuvius. The most common PDCs in recent volcanic disasters have had a light load of erupted particulate matter (dominated by ash) and have been well-mixed with air. Therefore, these PDCs are important for emergency planners to consider and they are the type studied for this paper. More dilute PDCs can be compared with dense PDCs, often termed pyroclastic flows, which are highly destructive with effects which can be difficult to mitigate (Baxter et al., 2005).

Baxter et al. (2005) devised for the first time a damage scale based on lateral dynamic pressure applied to the building shell by the directional flow of the PDC. The ingress of ash to the interior causing combustion of flammable contents such as furniture is identified as the main cause of damage at low dynamic pressure ranges. In the faster moving flow parts, where dynamic pressure is higher, particulates, debris, stones and missiles of all sorts become entrained in the main current and add to the destructive impact. The most vulnerable parts of the buildings are the openings, especially the windows, where glass panes or shutters can be readily be broken and then penetrated by hot ash. Petrazzuoli and Zuccaro (2004) calculated horizontal limit collapse loads for reinforced concrete structures around Vesuvius which could be affected by PDCs. Luongo et al. (2003) focus on a single house in Pompeii to identify factors influencing PDC damage from the AD 79 eruption.

Incorporating the variety of possible causes of deaths and building damage into models is a complex task and the necessary detailed investigations are all recent. Alberico et al. (2002) examine urban and population density as predictive variables for risk to and subsequent damage from PDCs. They do not examine how either specific buildings or building elements would be damaged, nor how specific casualties could result. Spence et al. (2004a, b) develop a detailed model to estimate building damage and casualties from a PDC affecting four villages around Mt. Vesuvius, Italy.
Specific modes of failure and causes of death were identified through engineering and medical analyses, some probabilistic and some deterministic. One PDC scenario is run producing deterministic casualty and building damage outcomes. This paper uses Spence et al. (2004a, b) as the basis for further probabilistic calculations.

Zuccaro and Ianniello (2004) analysed for the first time the complex process of interaction between a PDC and an urban area. One likely consequence is a shielding effect where the first row of buildings is severely damaged by a current, but protects the buildings behind, though the broken building elements can be entrained as missiles, thereby damaging subsequent buildings in the run-out. Further elaboration of the effect of urban areas on PDCs along with the possibility of urban firestorms resulting from a PDC's impact, are aspects currently under investigation. This paper does not consider these effects.

\subsection{Overview of this paper}

The literature review suggests a sequence of specific technical problems to be solved quantitatively with respect to the effects of PDCs on buildings and people (Fig. 1). When a PDC strikes an urban area, the main impacts are missiles, heat, and dynamic and isostatic pressure. Indoor fires caused by the flow temperature are a secondary, but important issue. In some cases external fires might be a significant factor too, but those are complex enough to require separate study and will not be addressed further here. In this paper, it is assumed that people outdoors will be killed when a PDC arrives, but that survival of people remaining indoors may be possible.

If a building collapses, it is assumed that every occupant is killed. For people inside buildings which do not collapse, the main factor which governs vulnerability is the resistance of openings. Glazing is assumed to be a building's weak point (Baxter et al., 2005), so probability density functions for window glass failure under the combination of the three loads are calculated (Sect. 2.2). Protection of windows with shutters, cyclone boards, or other forms of protection are discussed in the conclusion.

If an opening were penetrated, i.e. if glass breaks, some occupants would be killed instantly, while others would be able to retreat to an inner room or a non-penetrated room, where they might survive, or might be killed by subsequent fires. Alternatively, if no openings were penetrated, or if people were in an interior room, then infiltration of the hot gases carrying abundant fine particles would lead to casualties from the rising temperature (causing hyperthermia and burns, or asphyxiation from inhaling abundant hot ash particles). Estimates of likely casualties from these effects are given, in relation to measures of the PDC flow (pressure and temperature), and of the building's configuration.

This paper's results may be used to provide a basis for first-order estimates of casualties and building damage in an urban area impacted by a PDC, if parameters of the flow can 


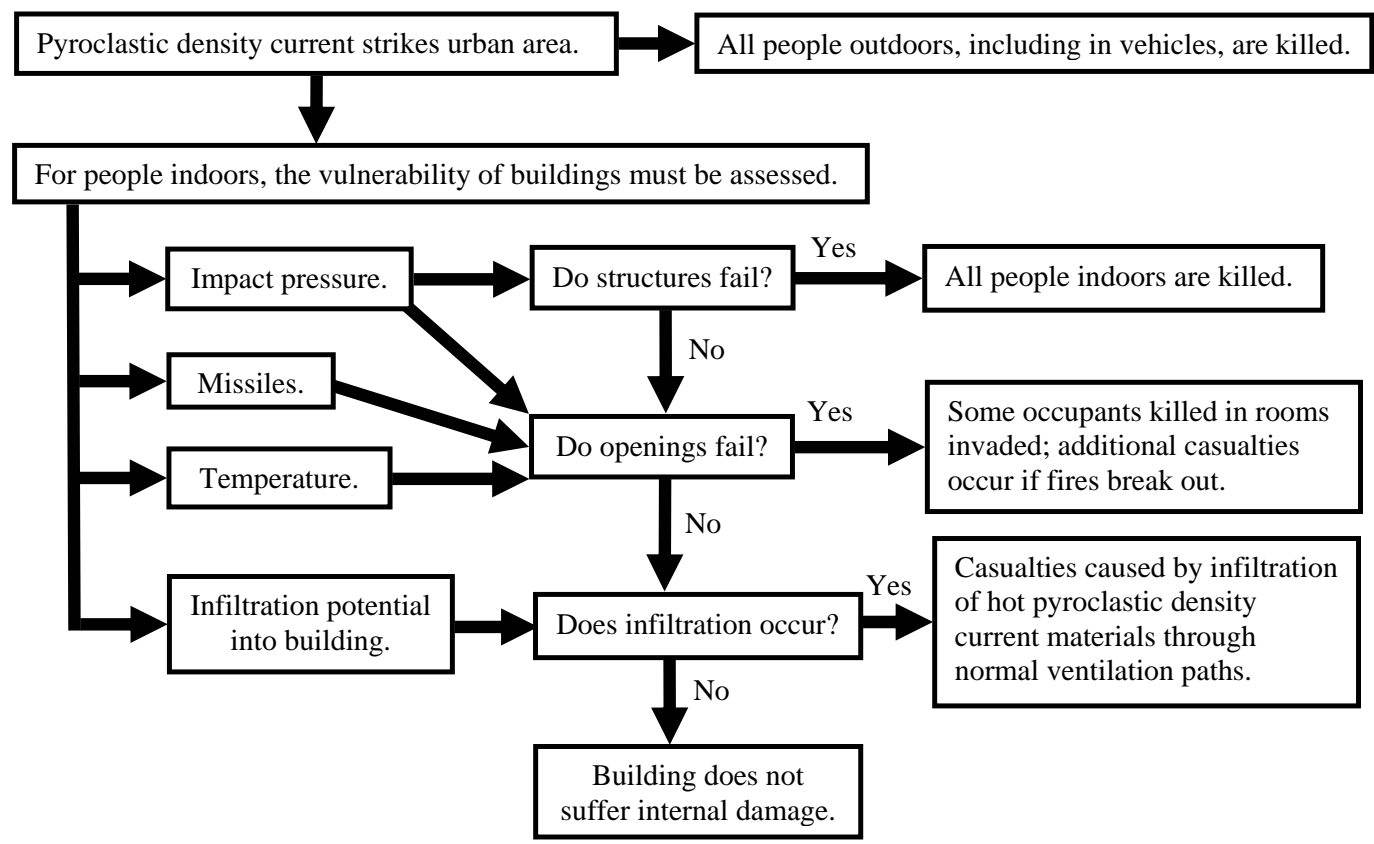

Fig. 1. Overview of factors that govern building and occupants' vulnerability to pyroclastic density currents.

be estimated and if the building stock's characteristics are known.

\section{Window failure}

\subsection{Combined effects of pressure and temperature}

The resistance of glazed openings to the pressures of PDCs was examined in earlier papers (Spence et al., 2004a, b), and the probability of failure as a function of flow pressure for small, typical and large openings derived in that work has been used here and extended. In this paper, we look at the effect on windows of the flow temperature and of the presence of missiles entrained in the flow.

Preliminary estimates of the probability of window failure due to temperature alone have been derived from work completed at the UK's Building Research Establishment (BRE) (Purser, 2005). Based on other standard forms of interaction curves related to material strengths, we propose a parabolic form of interaction between temperature and flow pressure such that:

$T i=T o\left(1-(P i / P o)^{2}\right)$

$P o$ and $T o$ are the pressure and temperature respectively required for a given probability of failure independently. $P i$ and $T i$ are the pressure and temperature respectively acting together to give that same failure probability. From Eq. (1), a set of failure probability distributions has been constructed as a function of pressure for different flow temperatures. These curves can be interpreted as constant offsets or shifts to the ambient temperature failure probability curve, where the shift, $\Delta P$, at each temperature is defined by Eq. (2):

$\Delta P=c \times T^{2}$

where $c$ has a value of $9 \times 10^{-5}, 4 \times 10^{-5}$, and $3 \times 10^{-5} \mathrm{~Pa} /{ }^{\circ} \mathrm{C}^{2}$ for small, typical and large windows respectively.

\subsection{Effect of entrained missiles}

Missile generation in a PDC depends on the aerodynamics of the flying debris and the availability of the potential missile objects. The damage done by flying debris depends upon the kinetic energy of the missile and the vulnerability of buildings and people to kinetic energy damage. Here, missiles are not considered to include ballistic rocks ejected from the volcanic vent or tephra-related bombs.

Wills et al. (1998) discuss the aerodynamics of flying debris with respect to cyclones and wind storms. They categorise debris into three types: compact objects for which the dimensions are of the same order of magnitude in three directions, sheet objects for which two dimensions are of the same order of magnitude but the third dimension is much smaller; and rods/poles for which two dimensions are of the same order of magnitude but are much smaller than the third dimension. Wills et al. (1998) then develop equations for the flow velocity that permits flight. The equations suggest that, in general, the size of an object that can be lifted by a PDC is proportional to the square of the velocity. The potential to cause damage is related to the kinetic energy of the moving object. If the flight velocity of the object is a fraction $\mathrm{J}$ of the 


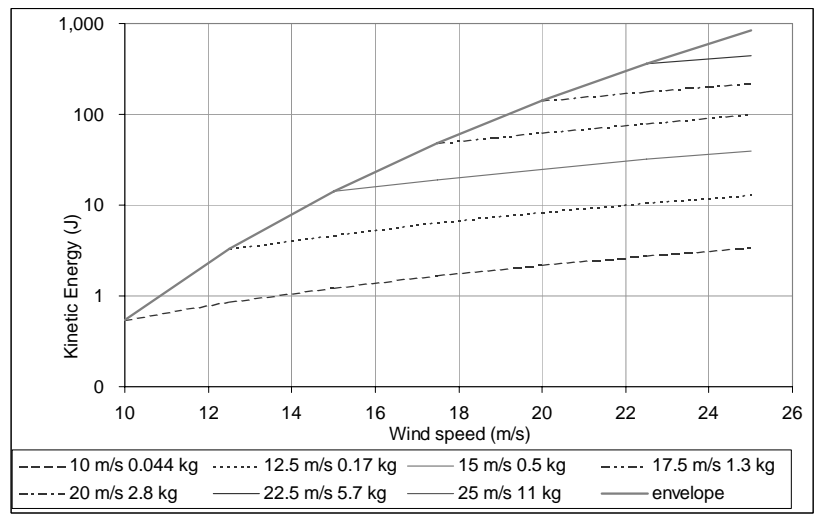

Fig. 2. Kinetic energy in wooden battens of slenderness ratio 25 . The wind speed is the sustained value of wind speed needed to maintain flight.

velocity of the density current (i.e. the object's flight velocity is $J \times U \mathrm{~m} / \mathrm{s}$ ), the equations can be re-arranged to give the kinetic energy $E_{k}$ of the largest likely flying object in the flow in relation to the flow velocity, $U$.

Compact objects : $E_{k}=1 / 16 \rho_{o}\left(\rho_{p f} C_{f} / \rho_{o} I g\right)^{3} J^{2} U^{8}$

Sheet materials : $E_{k}=1 / 4 \rho_{p f}\left(C_{f} J^{2} / I g\right) A U^{4}$

Rods and poles : $E_{k}=1 / 4 \rho_{p f}\left(C_{f} J^{2} / I g\right)(L d) U^{4}$

Figure 2, calculated for this paper, shows the kinetic energy of wooden battens of slenderness ratio 25 , where slenderness ratio is length divided by a representative lateral dimension. That illustrates the energy of the flying batten after the conditions for flight have been reached. The uppermost line "envelope" indicates the maximum energy of an object entrained in the flow for any velocity.

Wills et al. (1998) report that corrugated iron and plywood sheets commonly become missiles during hurricanes. Unanwa and McDonald (2000) examine debris from three tornadoes and provide data to show that $50 \times 100 \mathrm{~mm}$ timber length pose a major hazard. Such objects as failing building elements - including awnings, cladding and ornaments loose flower pots, mobile refuse bins, and terrace and street furniture are other debris sources which could become debris in a PDC.

The probability of missile impact on windows depends on the flow velocity, flow density, density of potential missiles in the area upflow from the window, and the area and orientation of windows. Missile impact will cause failure when a missile with sufficient kinetic energy to break the window strikes the window. It is assumed here that the energy required to break a glass panel is equal to the energy absorbed by the panel in its elastic deformation up to the point of failure. Given a Young's Modulus for glass of $65000 \mathrm{MPa}$ (ISE, 1999, and Makovička, 1998), the energy required to break a

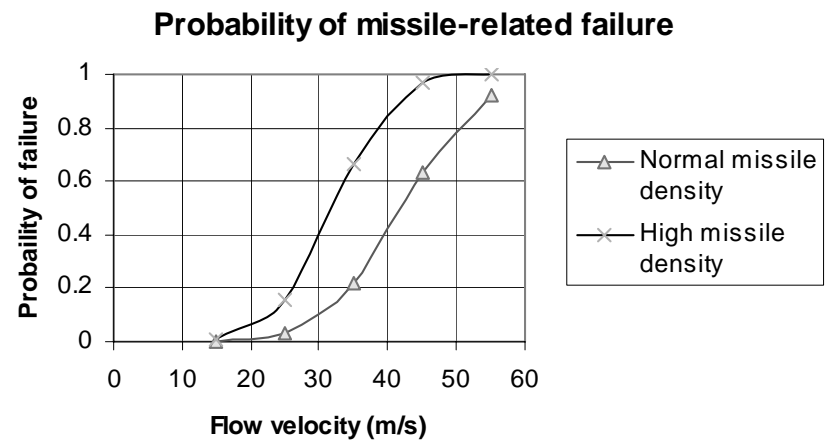

Fig. 3. Probability of missile-related window failure for ground floor windows at normal and high missile densities.

window ranges from 8 to $20 \mathrm{~J}$ for typical and large window panes of 3-4 mm thickness (see also Spence et al., 2004a, b). It can therefore be assumed that, at any given flow velocity, missiles with a kinetic energy less than $8 \mathrm{~J}$ will break few windows, missiles with a kinetic energy between 8 and $20 \mathrm{~J}$ will break some windows, and missiles with a kinetic energy above $20 \mathrm{~J}$ will break most windows. This is a relatively small energy transition range from few breakages to most breakages.

Based on these calculations, Table 1 gives missile masses, and an estimate of the probability of damaging missiles in the flow reaching both lower and upper storey windows, at various flow speeds, and using densities which are considered to be typical of those which might be found in dilute PDCs (Spence et al., $2007^{1}$ ). The probability of windows breaking due to the flow pressure alone is shown for comparison.

In the absence of any detailed data on missile availability, in Table 2 the availability of missiles is assessed according to two categories: either normal or high. Normal missile availability would apply to most urban environments where some of the items mentioned above are found; high missile availability would apply in situations where there are many loose building components, refuse items or plant material available for missiles. Numerical probabilities are then assigned: 5\% to "few", $30 \%$ to "some", and $70 \%$ to "many". The probability of missile failure at ground floor windows is then estimated (using the author's judgement, based on the data in Table 1) as a function of flow velocity based on the combined probability of missile availability, and the ability of the available missiles to reach the ground floor. Using the data points in Table 2, a best-fit cumulative normal distribution function was fitted in order to calculate the resulting probability of missile-related glass failure as a function of flow velocity for normal- and high-missile environments (Fig. 3).

\footnotetext{
${ }^{1}$ Spence, R. J. S., Komorowski, J.-C., Saito, K., Brown, A., Pomonis, A., Toyos, G., and Baxter, P.: Modelling the impact of a hypothetical sub-Plinian eruption at La Soufrière of Guadeloupe (West Indies), J. Volcanol., forthcoming, 2007.
} 
Table 1. Size ranges of potential missiles, and an estimate of the probability of damaging missiles in the flow reaching both lower and upper storey windows at given flow speeds and densities.

\begin{tabular}{|c|c|c|c|c|c|c|c|c|}
\hline \multirow[t]{2}{*}{$\begin{array}{l}\text { Flow } \\
\text { velocity } \\
(\mathrm{m} / \mathrm{s})\end{array}$} & \multicolumn{2}{|c|}{$\begin{array}{l}\text { Flow pressure }(\mathrm{kPa}) \text { at } \\
\text { given flow density }\end{array}$} & \multicolumn{2}{|c|}{$\begin{array}{l}\text { Probability of window } \\
\text { breaking due to pres- } \\
\text { sure at given flow den- } \\
\text { sity }\end{array}$} & \multirow{2}{*}{$\begin{array}{l}\text { Smallest } \\
\text { mass } \\
\text { missile } \\
\text { breaking } \\
\text { windows } \\
(\mathrm{kg})\end{array}$} & \multirow[t]{2}{*}{$\begin{array}{l}\text { Largest } \\
\text { missile } \\
\text { mass in } \\
\text { flight }(\mathrm{kg})\end{array}$} & \multirow{2}{*}{$\begin{array}{l}\text { Assumed prob- } \\
\text { ability of } \\
\text { damaging mis- } \\
\text { siles reaching } \\
\text { lower windows } \\
\text { (1.5 m above } \\
\text { ground level) }\end{array}$} & \multirow{2}{*}{$\begin{array}{l}\text { Assumed prob } \\
\text { ability of } \\
\text { damaging mis } \\
\text { siles reaching } \\
\text { upper windows } \\
\text { (>4 m above } \\
\text { ground level) }\end{array}$} \\
\hline & $3 \mathrm{~kg} / \mathrm{m}^{3}$ & $5 \mathrm{~kg} / \mathrm{m}^{3}$ & $3 \mathrm{~kg} / \mathrm{m}^{3}$ & $5 \mathrm{~kg} / \mathrm{m}^{3}$ & & & & \\
\hline 15 & 0.34 & 0.56 & 0.0 & 0.0 & 0.09 & 0.50 & 0 & 0 \\
\hline 25 & 0.94 & 1.56 & 0.0 & 0.029 & 0.03 & 11 & 50 & 10 \\
\hline 35 & 1.84 & 3.06 & 0.029 & 0.988 & 0.02 & 81 & 100 & 50 \\
\hline 45 & 3.04 & 5.06 & 0.885 & 1.0 & 0.01 & 365 & 100 & 100 \\
\hline
\end{tabular}

Table 2. Probability of missile failure at ground floor windows.

\begin{tabular}{lcccc}
\hline Flow velocity $(\mathrm{m} / \mathrm{s})$ & Normal & High & Normal & High \\
\hline 15 & None & None & 0.0 & 0.0 \\
25 & Few & Some & 0.02 & 0.15 \\
35 & Some & Many & 0.2 & 0.7 \\
45 & Many & Many & 0.7 & 0.9 \\
\hline Mean of normal distribution $(\mathrm{m} / \mathrm{s})$ & & & 42 & 32 \\
Standard deviation of normal distribution $(\mathrm{m} / \mathrm{s})$ & & & 9 & 7 \\
\hline
\end{tabular}

\subsection{Combined probability of window glass failure}

The joint probability of pressure-related (Spence et al., 2004a) and missile-related failure of glass can be combined as a function of flow pressure, using the joint failure probability relationship:

$p_{f}=1-\left(1-p_{f m}\right) \times\left(1-p_{f p}\right)$

where $p_{f}$ is the combined failure probability, $p_{f m}$ is the failure probability due to missiles alone, $p_{f p}$ is the failure probability due to flow pressure and temperature.

Figure 4 shows the joint failure probability of missilerelated failure and failure due to dynamic pressure alone as a function of dynamic pressure, assuming a flow density of $5 \mathrm{~kg} / \mathrm{m}^{3}$, for typical windows, in an environment of normal missile availability.

\section{Human casualties from failure of openings}

This section proposes a way to estimate the proportion of human casualties (deaths and serious injuries) which will occur in dwellings which have been invaded by PDC materials resulting from the failure of one or more windows or other openings. The scenario derives from earlier work, based on

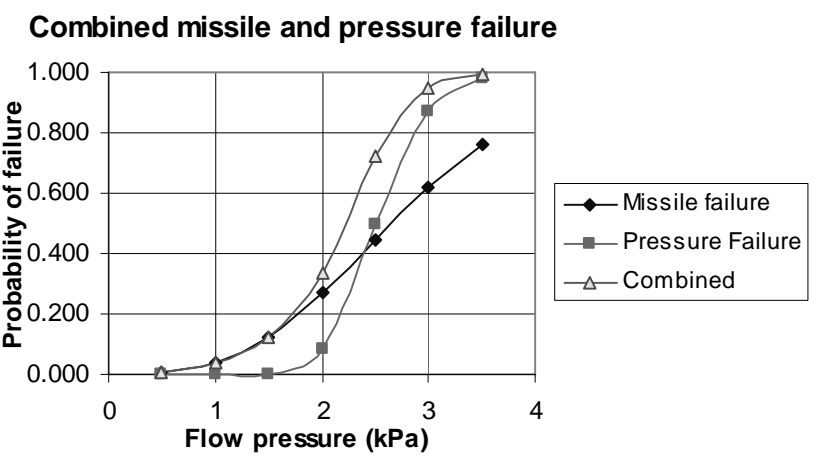

Fig. 4. Separate and joint failure probabilities for typical windows for missile-related and pressure-related failure for a flow density of $5 \mathrm{~kg} / \mathrm{m}^{3}$.

observation at Montserrat (Spence et al., 2004a; Baxter et al., 2005), as well as extensive experience of fire spread at BRE (Purser, 2002, 2005).

The ingress of hot PDC materials is expected to be immediately life-threatening to anyone in the room directly invaded. Immediate casualty rates among those people will depend primarily on the temperature of the flow materials. Depending on the internal arrangement of the dwelling, and 


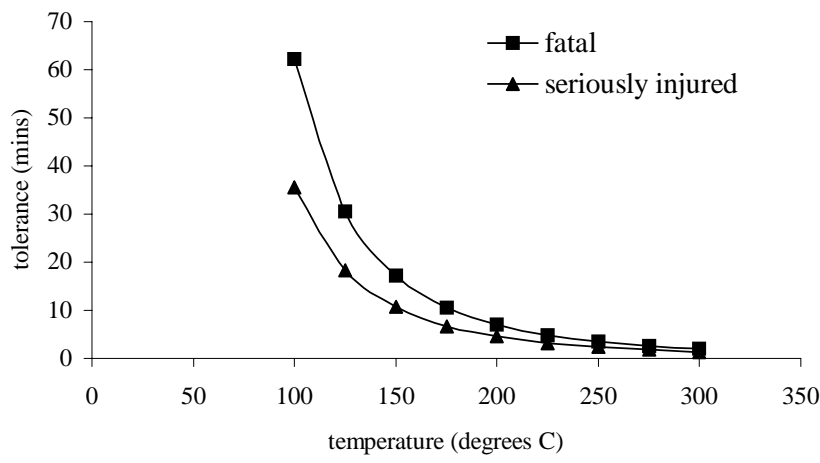

Fig. 5. Tolerance time (i.e. average time required to result in death or serious injury) for a person exposed to a constant indoor air temperature.

the number of windows which fail, some of the occupants may initially escape to other areas of the dwelling. However, a secondary effect if the temperature of the flow materials is high enough, is that fires will break out and spread, threatening those who have escaped the room initially impacted. This will cause additional casualties.

There are a number of variables in this scenario. The authors' judgement on the human casualties which are likely to result are summarised, for a simplified set of assumptions, in Table 3. Three sets of dwelling configuration are first distinguished: open-plan dwellings, dwellings which are compartmented (i.e. divided into a number of rooms, separated by doors), and apartments, which are here assumed to be compartmented. A secondary consideration is the number of windows which have failed, allowing ingress of PDC materials. The table distinguishes, for the compartmented dwellings, cases where one or two windows have failed, and cases where three or more have failed. For cases where just one or two windows have failed, the table distinguishes PDC materials according to their temperature. Temperatures below $250^{\circ} \mathrm{C}$, though sufficient to cause casualties to people directly exposed to the temperature, are much less likely to cause fires than those above $250^{\circ} \mathrm{C}$. Thus, six cases are distinguished, which we consider to include the important cases we have found in our studies of the building stocks around major European explosive volcanoes (Spence et al., 2004a, b; Spence et al., 2005a, b; Martí et al., 2007²).

The first three rows of Table 3 set out our estimates of the casualties arising directly as a result of window failure. In open-plan dwellings and those in which three or more windows fail, all occupants are affected, regardless of temperature, while in compartmented dwellings in which only one or two windows fail, casualty rates are expected to depend

\footnotetext{
${ }^{2}$ Martí, J., Spence, R. J. S., Calogero, E., Ordoñez, A., Felpeto, A., and Baxter, P. J.: Estimating Building Exposure and Impact from Volcanic Hazards in Icod de los Vinos, Tenerife, J. Volcanol., forthcoming, 2007.
}

on temperature. The next two rows give our estimates of the probability of fire ignition, and then fire spread. Probability of fire ignition depends on temperature, but probability of spread depends on the building configuration. Of some importance is the potential in apartment blocks for fire to spread externally via the windows from one apartment to an apartment on the level above, reflected in a higher probability of spread for apartment blocks. The following three rows show the casualty estimates, given a fire, among those who survived the initial impact. Survival rates, given the occurrence of a fire, are taken from the BRE's experience of domestic fires; and casualties among those affected are divided equally among those killed and those seriously injured. Finally, the total casualties shown in the last three rows, are obtained by adding the casualties directly from window failure to those resulting from the subsequent fires.

\section{Human casualties from infiltration}

\subsection{Casualty estimation}

Even when openings remain intact, indoor casualties can occur during PDCs as a result of infiltration of the hot particleladen gases into a dwelling through the normal ventilation routes. The internal conditions will be related to the temperature and duration of the flow external to the building and to the ventilation rate of the building. This section proposes a way to estimate the infiltration casualties based on an understanding of these variables.

Although the particle content of the PDC materials may cause breathing problems, it is expected that indoor casualties will be primarily caused by heatstroke. Based on Purser (2005) we propose the following expressions for the tolerance time required to cause death or serious injury at a constant temperature, $\mathrm{T}$ :

$t_{\text {injury }}=3 \times 10^{7} \times T^{-2.96}$

$t_{\text {fatal }}=10^{8} \times T^{-3.11}$

where $t_{\text {injury }}$ is the time required (minutes) for $50 \%$ probability of serious injury, $t_{\text {fatal }}$ is the time required for $50 \%$ probability of death amongst occupants, and $T$ is temperature. These expressions are plotted in Fig. 5.

Because the internal temperature is not constant, but varies over time, we use the notion of a dose per unit time $(\Delta D$ $\left[\mathrm{min}^{-1}\right]$, which is defined as the inverse of the tolerance time $\left(t_{\text {injury }}\right.$ or $\left.t_{\text {fatal }}\right)$. The total dose $(D)$ after time $t$, is then defined as the cumulative sum of all unit doses over a period of exposure at varying temperature. We then estimate the probability of death $\left(P_{\text {death }}\right)$ (or serious injury) as a function of total dose with a ramp function as follows:

$$
\begin{aligned}
& P_{\text {death }}=0 \text { if } 0 \leq D<0.5 t_{\text {fatal }} \\
& P_{\text {death }}=D-0.5, \text { if } 0.5 t_{\text {fatal }} \leq D \leq 1.5 t_{\text {fatal }} \\
& P_{\text {death }}=1, \text { if } D>1.5 t_{\text {fatal }}
\end{aligned}
$$


Table 3. Proposed casualty vulnerability, expressed as a ratio of occupants, resulting from pyroclastic density current damage to buildings and ingress of hot ash.

\begin{tabular}{|c|c|c|c|c|c|c|c|}
\hline \multirow{2}{*}{\multicolumn{2}{|c|}{$\begin{array}{c}\text { Dwelling plan } \\
\text { Failure of: }\end{array}$}} & \multirow{3}{*}{$\begin{array}{c}\text { Open plan } \\
\begin{array}{c}1-3 \\
\text { windows }\end{array} \\
\text { N/A }\end{array}$} & \multicolumn{3}{|c|}{ Compartmented } & \multirow{2}{*}{\multicolumn{2}{|c|}{$\begin{array}{c}\begin{array}{c}\text { Apartment blocks } \\
\text { Compartmented }\end{array} \\
1-2 \text { windows }\end{array}$}} \\
\hline & & & \multicolumn{2}{|c|}{ 1-2 windows } & \multirow{2}{*}{$\begin{array}{c}\begin{array}{c}3 \text { or more } \\
\text { windows }\end{array} \\
\text { N/A }\end{array}$} & & \\
\hline Tempe & ture & & $T<250^{\circ} \mathrm{C}$ & $T \geq 250^{\circ} \mathrm{C}$ & & $T<250^{\circ} \mathrm{C}$ & $T \geq 250^{\circ} \mathrm{C}$ \\
\hline \multirow{4}{*}{$\begin{array}{l}\text { Casualties directly from } \\
\text { window failure }\end{array}$} & Unaffected & 0.00 & 0.75 & 0.25 & 0.00 & 0.75 & 0.25 \\
\hline & Death or serious injury & 1.00 & 0.25 & 0.75 & 1.00 & 0.25 & 0.75 \\
\hline & Dead & 0.50 & 0.13 & 0.38 & 0.50 & 0.13 & 0.38 \\
\hline & Seriously injured & 0.50 & 0.13 & 0.38 & 0.50 & 0.13 & 0.38 \\
\hline \multirow{2}{*}{\multicolumn{2}{|c|}{$\begin{array}{l}\text { Probability of fire ignition } \\
\text { Probability of fire spread }\end{array}$}} & 0.90 & 0.10 & 0.90 & 0.90 & 0.10 & 0.90 \\
\hline & & 0.90 & 0.66 & 0.66 & 0.90 & 0.75 & 0.75 \\
\hline \multirow{4}{*}{ Casualties given fire } & Unaffected & 0.02 & 0.10 & 0.10 & 0.02 & 0.10 & 0.10 \\
\hline & Death or serious injury & 0.98 & 0.9 & 0.90 & 0.98 & 0.90 & 0.90 \\
\hline & Dead & 0.49 & 0.45 & 0.45 & 0.49 & 0.45 & 0.45 \\
\hline & Seriously injured & 0.49 & 0.45 & 0.45 & 0.49 & 0.45 & 0.45 \\
\hline \multirow{4}{*}{ Total casualties } & Unaffected & 0.00 & 0.71 & 0.12 & 0.00 & 0.70 & 0.10 \\
\hline & Death or serious injury & 1.00 & 0.29 & 0.88 & 1.00 & 0.30 & 0.90 \\
\hline & Dead & 0.50 & 0.15 & 0.44 & 0.50 & 0.15 & 0.45 \\
\hline & Seriously injured & 0.50 & 0.15 & 0.44 & 0.50 & 0.15 & 0.45 \\
\hline
\end{tabular}

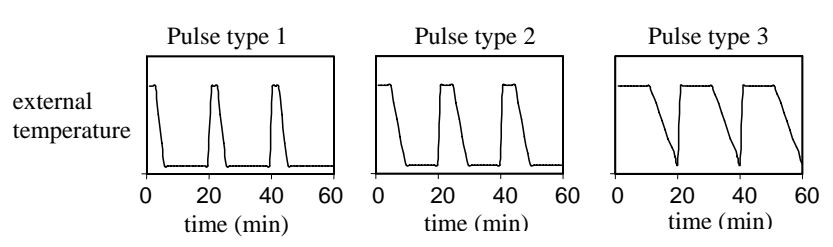

Fig. 6. Temperature time relationships for the three PDC pulses considered (peak temperatures vary).

\subsection{Internal temperature in dwellings}

To estimate injury and fatality rates for a given building and PDC conditions we need to find how indoor temperature responds to the external conditions. To do this, we have examined alternative PDC pulses of three types (Fig. 6) which on the basis of previous modelling work (Todesco et al., 2002) we consider plausible. Three shapes of pulse and two alternative peak temperatures $\left(300^{\circ} \mathrm{C}\right.$ and $\left.600^{\circ} \mathrm{C}\right)$ have been examined. All three pulses have a repetition time of $20 \mathrm{~min}$, but have different lengths. Pulse type 1 lasts $3 \mathrm{~min}$, Pulse type 2 lasts $5 \mathrm{~min}$ and Pulse type 3 lasts $10 \mathrm{~min}$, with an assumed instantaneous rise, but each with a ramping-down period to ambient temperature of the same length of time as the pulse duration. We have also examined a number of alternative ventilation rates from 4 to 10 air changes per hour $(\mathrm{ac} / \mathrm{h})$, the range we expect in the building stocks we have examined.

To model the internal conditions, a simple time-stepping model has been adopted, in which the volumetric inflow is
Pulse type $1600 \mathrm{deg}$

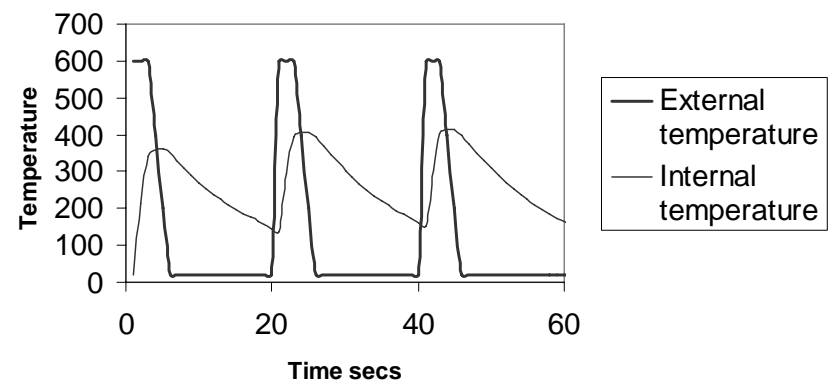

Fig. 7. Internal and external temperature for pulse type 1, max temperature $600^{\circ} \mathrm{C}$.

calculated in each time-step (typically one minute), and the internal temperature at the end of the time interval is calculated assuming complete mixing of the current internal air with the incoming gases in a single internal volume. During the first two minutes of the pulse, the ventilation rate is assumed to be increased by a factor of 5 to allow for the shortterm build-up of isostatic pressure which occurs at the onset of each PDC pulse. Figure 7 shows the external temperatures and the resulting internal temperatures for Pulse type 1 at an assumed ventilation rate of $4 \mathrm{ac} / \mathrm{h}$.

The results of this model (Fig. 7) suggest that at the assumed infiltration rates, temperatures rise quite quickly to a temperature between $50 \%$ and $70 \%$ of the external temperature; remain at that temperature for the duration of the pulse 
Table 4. Probability of death for a ventilation rate of 4 ac/hour using pulses of 3,5 and $10 \mathrm{~min}$, and the corresponding temperature flux $(T F)$ calculated with the best fit curve: $T F=\left(T_{\text {ext }}-120\right) \times$ pulse length $\times 1.5$.

\begin{tabular}{lccc}
\hline $\begin{array}{l}\text { Length of pulse } \\
\text { (min) }\end{array}$ & $\begin{array}{c}T_{\text {ext }} \\
\left({ }^{\circ} \mathrm{C}\right)\end{array}$ & $\begin{array}{c}\text { Probability of death } \\
\text { after 60 min }\end{array}$ & $\begin{array}{c}T F \\
\left({ }^{\circ} \mathrm{C} \times \min \right)\end{array}$ \\
\hline 3 (type 1) & 250 & 0.07 & 585 \\
& 300 & 0.45 & 810 \\
5 (type 2) & 350 & 0.99 & 1035 \\
& 200 & 0.06 & 600 \\
& 250 & 0.58 & 975 \\
10 (type 3) & 275 & 0.94 & 1163 \\
& 160 & 0.11 & 600 \\
& 190 & 0.53 & 1050 \\
& 210 & 0.89 & 1350 \\
\hline
\end{tabular}

and then start to decline gradually. The onset of the next pulse leads to an increase to a higher peak temperature, the increment depending on the interval between pulses; but the impact of the first pulse is likely to be the most important.

\subsection{Casualties as a function of external temperature}

The internal temperature calculation model has been used in conjunction with the casualty model described above to examine the relationship between external temperature and casualties, and to enable the prediction of deaths and casualties as a function of external temperature and time of flow. We define the external temperature flux $(T F)$ corresponding to any length of PDC pulse as:

$T F=\left(T_{\text {ext }}-T_{0}\right) \times$ length of pulse $\times 1.5$

where $T_{\text {ext }}$ is the peak external temperature, the length of the pulse is the dwell time at the peak temperature $T_{0}$ is a base temperature corresponding to the onset of casualties and the factor 1.5 accounts for half of the time required by the temperature to ramp down to ambient temperature.

An empirical approach was used to find a relationship between the probability of death or serious injury as a function of $T F$ and ventilation rate, and also the best value of $T_{0}$, using Eqs. (7) to (11). We did several runs with different peak temperatures, pulses of 3, 5 and $10 \mathrm{~min}$ and ventilation rates of 2,4 and $10 \mathrm{ac} / \mathrm{h}$ to compute the probability of death and the probability of serious injury after 60 minutes. Some results are shown in Table 4.

Adjusting the factor $T_{0}$ to reduce to a minimum the differences between the results for the different pulse lengths, we found the best-fit values of $T_{0}$ (Eq. 12) to be $120^{\circ} \mathrm{C}$ and $100^{\circ} \mathrm{C}$ for death and serious injury, respectively. Finally, we fitted a normal probability function to enable the prediction

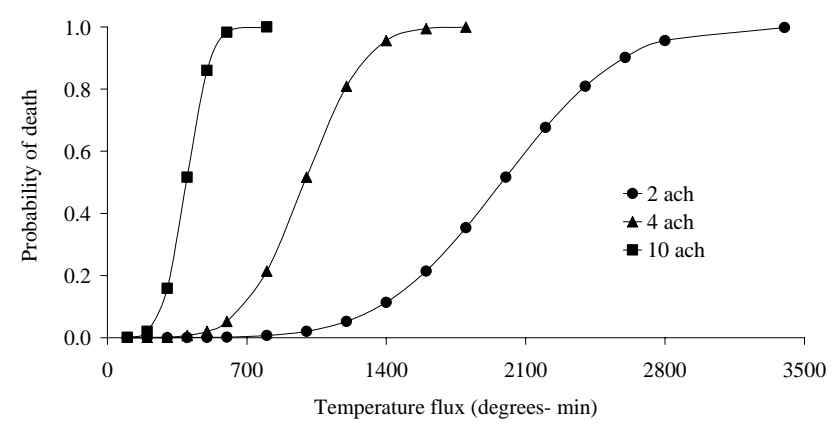

Fig. 8. Probability of death as a function of external temperature flux for different ventilation rates.

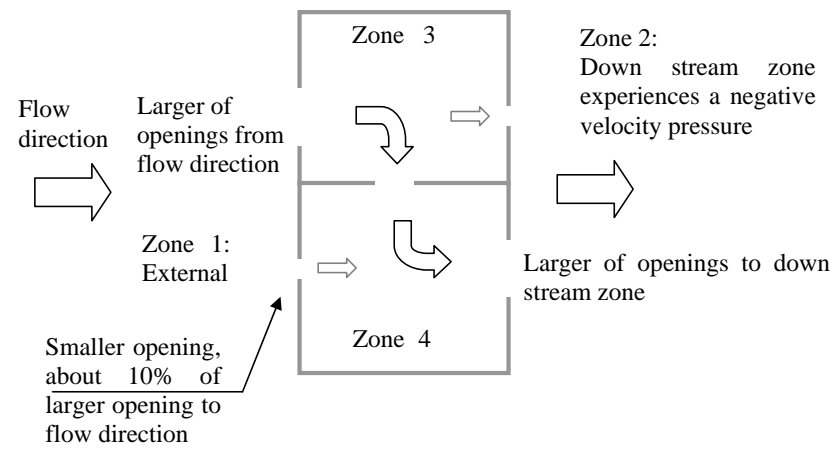

Fig. 9. Arrangement of zones for two internal-zone model.

of the probability of death and of serious injury based on the temperature flux and the ventilation rate:

$P_{\text {death } / \text { serious injury }}=\Phi\left(T F_{\mu}, T F_{\sigma}\right)$

where $\Phi(\mu, \sigma)$ is the cumulative normal distribution with mean value $\mu$ and standard distribution $\sigma$.

For the probability of death, we found that $T F_{\mu}=3960 / V R$ and $T F_{\sigma}=0.24 \times T F_{\mu}$, while for the probability of serious injury, $T F_{\mu}=3380 / V R$ and $T F_{\sigma}=0.28 \times T F_{\mu}$, where $V R$ is the typical ventilation rate of the building, expressed in air changes per hour.

The resulting curves for calculating the probability of death in buildings with ventilation rates of 2,4 , and $10 \mathrm{ac} / \mathrm{h}$ are shown in Fig. 8. Similar curves can be obtained for the probability of serious injury.

\section{Multi-zone models}

\subsection{Modelling method}

The above analysis assumes a simple one-zone building interior with a single ventilation rate through the envelope. To investigate the possible benefits of sheltering provided by internal spaces, a more sophisticated computational fluid dynamics model has been employed to calculate the infiltration 


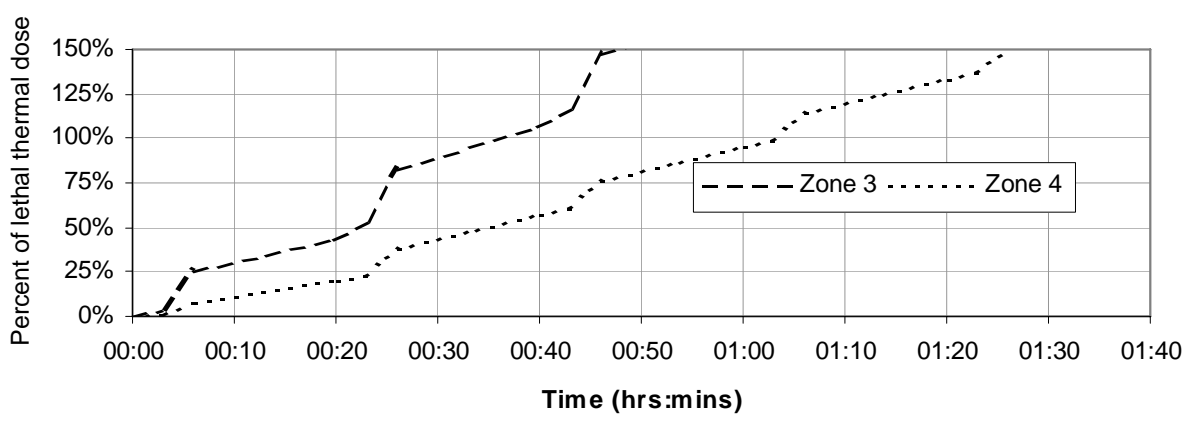

Fig. 10. Two-zone model. Percent of lethal thermal dose as a function of time in each of the zones for the model of Fig. 6. (Assumes an external PDC pulse of $300^{\circ} \mathrm{C}$ for 3 minutes (Type 1) repeated every $20 \mathrm{~min}$ and opening area of $0.01 \mathrm{~m}^{2}$ both to external zone and between internal zones (equivalent to $4.5 \mathrm{ac} / \mathrm{h}$ at $50 \mathrm{~Pa}$ test pressure).)

of pyroclastic materials into buildings for different assumed building configurations, and to compare the thermal dose experienced by occupants in different zones.

The indoor particle concentration rise and air temperature rise were predicted with fluid-dynamic modelling using the software Phoenics from CHAM (Concentration Heat \& Momentum Ltd, Wimbledon Village, U.K.) along with other calculations using the standard Newtonian equations for mass transfer and momentum. This analysis allows for increased velocity pressure from the flow, fluctuations in isostatic pressure, and the effect of particle concentration. A Microsoft Visual Basic programme was written that models the event in small time steps and records the parameters in several connected zones within a building.

The model uses temperature, isostatic pressure and particle concentration for a PDC in order to predict the temperature and thermal dose in each zone. The programme permits the user to select an event definition, a zone definition, and an output file for the simulation results. The simulation then solves basic flow and energy equations for each time step and writes the data to the output file.

Simulations using the pulses in Fig. 6 were run with two pulse velocities: $15 \mathrm{~m} / \mathrm{s}$ and $25 \mathrm{~m} / \mathrm{s}$. Each pulse repeats every $20 \mathrm{~min}$. Up to six cycles (two hours) was modelled. The particle concentration was fixed at $0.01 \%$ for each event. Three pulse types, two pulse peak temperatures, and two flow velocities yield twelve possible permutations for each assumed building model. Three different building models were also examined with different ventilation rates . A regression analysis was developed to predict the proportion of fatal dose experienced for different inputs for a single zone model.

\subsection{Two internal zone simulations}

Configurations with two zones were tested with a Type 1 (Fig. 6) pulse at $300^{\circ} \mathrm{C}$. The model was symmetrical, with the two internal zones each having 3 effective openings (Figs. 9 and 10). The total upstream and downstream infiltration areas are the same as the single-zone models with $90 \%$ of the

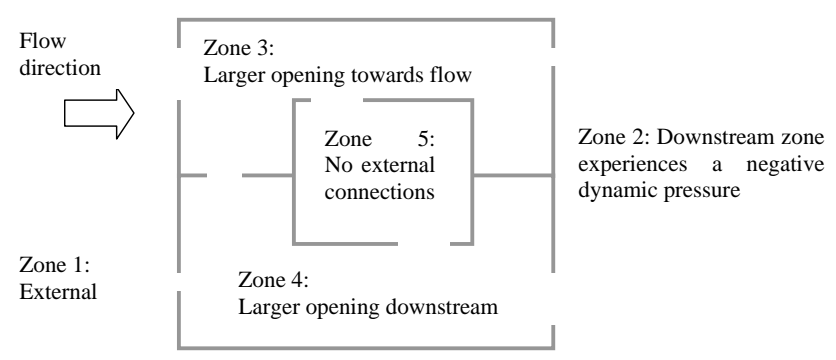

Fig. 11. Arrangement of zones and openings for three-zone model.

opening from each external zone being to different internal zones. The two zones are also linked by one of three equivalent area openings used in the single zone models. Thus, nine configurations were specified.

The configuration is designed so that the predominant flow is from the upstream zone, Zone 1, through Zone 3 to Zone 4 and out to the downstream zone, Zone 2 . The temperature rises rapidly in Zone 3 but the rate of increase in Zone 4 is attenuated since the temperature in zone 3 is less than the external zones (Fig. 10).

\subsection{Three internal zone simulation}

A partially-sealed refuge within a building is likely to provide better protection from a PDC. An additional zone was added to the model to evaluate the effect of a separate space with no connection to the outside (Figs. 11 and 12).

As expected, temperatures and subsequent rates of thermal dose decrease in the internal zone. A comparison was made of the effect of increasing the extent of sealing in the internal space (Fig. 12).

The computational model described permits the configuration of the vulnerable building to be considered for infiltration and temperature rise rates. It shows a near-linear relationship between the vulnerability of occupants in any zone and the ventilation exchange rate of that zone. It also suggests (Figs. 10,12) increasingly effective protection from 


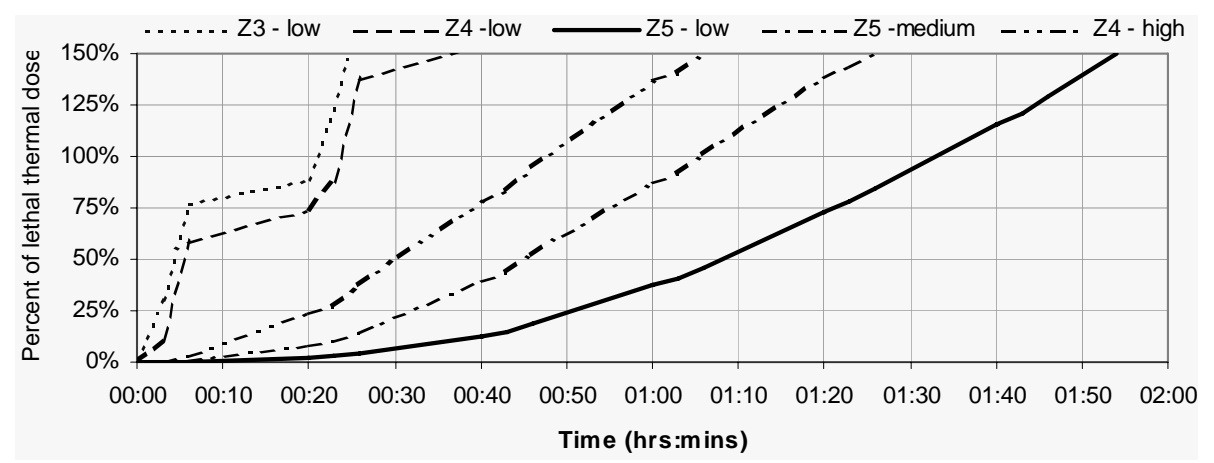

Fig. 12. Three-zone model. Percent of lethal thermal dose as a function of time and the degree of sealing of the internal envelope. (Assumes an external PDC pulse of $300^{\circ} \mathrm{C}$ for $3 \mathrm{~min}$ (Type 1) repeated every $20 \mathrm{~min}$, and opening areas both to external zone and between internal zones of $0.01 \mathrm{~m}^{2}$ for low, $0.02 \mathrm{~m}^{2}$ for medium, and $0.04 \mathrm{~m}^{2}$ for high (equivalent to $4.5,9.0 \mathrm{and} 18 \mathrm{ac} / \mathrm{h}$ at $50 \mathrm{~Pa}$ test pressure).)

barriers to flow through the building and the creation of refuges.

These results suggest that creating reasonably-sealed refuges in buildings is more effective for saving lives than trying to seal the entire external envelope. In well-ventilated buildings, the temperature of the outer zones may drop below the temperature in the refuge after the peak of external temperature has passed. Active control of the ventilation may in theory be able to decrease casualty rates, but occupants would have to be aware of the distinction between a pause between PDC events, (when they might think about opening internal doors), and the "all clear", when it would be safe leave the refuge. These results, however, do not consider fire.

\section{Conclusions}

A set of vulnerability models and relationships to enable the calculation of expected number of casualties and fatalities by pyroclastic density currents in an urban area has been proposed. New analyses have been presented regarding the threats from missiles entrained by the PDC and the infiltration of ash and hot air, with or without window breakage. The state of damage to windows has been used to estimate casualties.

The research results suggest possible mitigation measures which are likely to be relevant irrespective of the effects of turbulence and fire:

- Reduce the amount of potential missiles in the urban environment.

- Strengthen window glass, particularly in openings facing the volcano.

- Add shutters to all glass openings and ensure that they are shut before evacuating or when a PDC warning is issued.
Other potential mitigation measures could be considered, but they should not be implemented until further research has been conducted on turbulence in PDCs and fire from PDCs so that these effects have been incorporated into the models:

- Create a well-sealed internal room as a refuge.

- If a structure does not have a sealable internal room, consider evacuating residents to a structure which does.

- Sealing the building envelope could be an alternative, but would rarely be as effective a robust internal room.

- New structures should be built with a sealable internal room.

A common rating and labelling procedure for buildings and communities could be considered as an option for communicating PDC vulnerability and for assisting people in making informed decisions about their safety.

In applying and communicating mitigation options for PDCs, care must be taken that other vulnerabilities are not exacerbated. The impacts on social vulnerability would need to be examined. For example, suggesting that an action provides houses resistant to PDCs could encourage people to stay put during a volcanic eruption, potentially exposing them to other life-threatening volcanic hazards such as tephra. Any strategy to combat PDC vulnerability should be linked to overall building safety including all volcanic and non-volcanic hazards threatening a community. 


\section{Appendix}

\section{Symbols and abbreviations}

A Area of an sheet-shaped object. $\left[\mathrm{m}^{2}\right]$

$\mathrm{ac} / \mathrm{h} \quad$ Air changes per hour, a measure of how well a room is ventilated. $\left[\mathrm{h}^{-1}\right]$

c Offsetting constant for Eq. (2). $\left[\mathrm{Pa} /{ }^{\circ} \mathrm{C}^{2}\right]$

$C_{f} \quad$ Force coefficient applicable to different shapes of potential missiles in PDC (compact objects $=1$, sheets $=0.3$, rods $=0.6)$. $[-]$

$d \quad$ Rod diameter for Eq. (5). [m]

$D \quad$ Total dose of heat received after time $t$, calculated as the cumulative sum of all $\Delta D$ over a period of exposure at varying temperatures. $\left[\mathrm{min}^{-1}\right.$ ]

$\Delta D \quad$ Dose of heat received per unit time. $\left[\mathrm{min}^{-1}\right]$

$E_{k} \quad$ Kinetic energy of a moving object. [J]

$g \quad$ gravitational acceleration on Earth. [9.81 m/s $\left.\mathrm{s}^{2}\right]$

I Fixity coefficient for small objects in a built environment, assumed equal to 1 for loose objects, although if an object's fixing strength is less then its weight, I might be less than one. Better restrained objects have $I>1[-]$

$J \quad$ A fraction of a PDC's velocity representing the flight velocity of an object transported by the pyroclastic flow, i.e. the object's flight velocity is $J \times U \mathrm{~m} / \mathrm{s}$. [-]

$L \quad$ Rod length for Eq. (5). [m]

PDC Pyroclastic density current.

$p_{f} \quad$ The combined failure probability for missiles and PDC pressure and temperature. [-]

$p_{f m} \quad$ Failure probability due to missiles. [-]

$p_{f p} \quad$ Failure probability due to PDC pressure and temperature. [-]

$P_{\text {death }} \quad$ Probability of death. [-]

$P i \quad$ Pressure imposed by a PDC required for glazing to fail at temperature $T i$. [kPa]

$P o \quad$ Pressure imposed by a PDC required for glazing to fail without considering temperature influences. [kPa]

$t \quad$ An arbitrary time period. [time]

$T \quad$ Temperature. $\left[{ }^{\circ} \mathrm{C}\right]$

TF Temperature flux, the amount of heat which has been experienced in a location. $\left[{ }^{\circ} \mathrm{C}\right.$-min]

$\mathrm{Ti} \quad$ Pressure imposed by a PDC required for glazing to fail at pressure $\mathrm{Pi} .\left[{ }^{\circ} \mathrm{C}\right]$

To Temperature imposed by a PDC required for glazing to fail without considering pressure influences. $\left[{ }^{\circ} \mathrm{C}\right]$

$U \quad$ PDC velocity. [m/s]

$\mu \quad$ Arithmetic mean or data or mean of a normal distribution $\Phi$. [any units]
$\rho_{p f}$
Pyroclastic flow density. $\left[\mathrm{kg} / \mathrm{m}^{3}\right]$
$\rho_{o} \quad$ Density of an object such as a potential mis- sile. $\left[\mathrm{kg} / \mathrm{m}^{3}\right]$
$\sigma \quad$ Standard deviation of data or of a normal dis- tribution $\Phi$. [any units]
$\Phi(\mu, \sigma) \quad$ Normal distribution with mean $\mu$ and stan- dard deviation $\sigma$. [any units]

Acknowledgements. The authors thank A. Neri, J. Gaspar, J.-C. Komorowski, J. Martí, and their teams for assistance which made this work possible. R. Blong provided helpful suggestions and the EGU Editorial Office provided support. The European Union provided the funding which made this research possible through the project Explosive Eruption Risk and Decision Support for EU Populations Threatened by Volcanoes (EXPLORIS) EVR1-200100047.

Edited by: J. Martí

Reviewed by: R. Blong

\section{References}

Alberico, I., Lirer, L., Petrosino, P., and Scandone, R.: A methodology for the evaluation of long-term volcanic risk from pyroclastic flows in Campi Flegrei (Italy), J. Volcanol., 116, 63-78, 2002.

Baxter, P. J.: Medical effects of volcanic eruptions. 1. Main causes of death and injury, B. Volcanol., 52, 532-544, 1990.

Baxter, P. J., Boyle, R., Cole, P., Neri, A., Spence, R. J. S., and Zuccaro, G.: The impacts of pyroclastic surges on buildings at the eruption of the Soufrière Hills volcano, Montserrat, B. Volcanol., 67, 292-313, 2005.

Blong, R. J.: Volcanic Hazards: A Sourcebook on the Effects of Eruptions, Academic Press, London, UK, 1984.

Eisele, J. W., O'Halloran, R. L., Reay, D. T., Lindholm, G. R., Lewman, L. V., and Brady, W. J.: Deaths during the May 18, 1980, eruption of Mount St Helens, New Eng. J. Med., 305, 931-936, 1981.

ISE: Structural Use of Glass in Buildings, Institution for Structural Engineers, London, UK, 1999.

Luongo, G., Perrotta, A., Scarpati, C., De Carolis, E., Patricelli, G., and Ciarallo, A.: Impact of the AD 79 explosive eruption on Pompeii, II. Causes of death of the inhabitants inferred by stratigraphic analysis and areal distribution of the human casualties, J. Volcanol., 126, 169-200, 2003.

Makovička, D.: Shock Wave Load of Window Glass Plate Structure and Hypothesis of Its Failure, in: Structures Under Shock and Impact V (Fifth International Conference, SUSI 98), edited by: Jones, N., Talaslidis, D. G., Brebbia, C. A., and Manolis, G. D., Computational Mechanics Publications, Southampton, UK and Boston, USA, 43-52, 1998.

Mastrolorenzo, G., Petrone, P. P., Pagano, M., Incoronato, A., Baxter, P. J., Canzanella, A., and Fattore, L.: Herculaneum Victims of Vesuvius in AD 79, Nature, 410, 769-770, 2001.

Petrazzuoli, S. M. and Zuccaro, G.: Structural resistance of reinforced concrete buildings under pyroclastic flows: A study of the Vesuvian area, J. Volcanol., 133, 353-367, 2004.

Purser, D. A.: Toxicity Assessment of Combustion Products, in: The SFPE Handbook of Fire Protection Engineering, 3rd ed., 
edited by: DiNenno, P. J., National Fire Protection Association, Quincy, Maryland, 2/83-2/171, 2002.

Purser, D. A.: Vulnerability of humans to fire and pyroclastic flows, EXPLORIS Deliverable 4.5, The Martin Centre, Cambridge University, 2005.

Simkin, T., Siebert, L., and Blong, R.: Volcano Fatalities - Lessons from the Historical Record, Science, 291, 255, 2001.

Spence, R. J. S., Baxter, P. J., and Zuccaro, G.: Building vulnerability and human casualty estimation for a pyroclastic flow: a model and its application to Vesuvius, J. Volcanol., 133, 321343, 2004a.

Spence, R. J. S., Zuccaro, G., Petrazzuoli, S., and Baxter, P. J.: Resistance of Buildings to Pyroclastic Flows: Analytical and Experimental Studies and Their Application to Vesuvius, Nat. Hazards Rev., 5(1), 48-59, 2004b.

Spence, R. J. S., Kelman, I., Baxter, P. J., Zuccaro, G., and Petrazzuoli, S.: Residential building and occupant vulnerability to Tephra Fall, Nat. Hazards Earth Syst. Sci., 5, 477-494, 2005 a.
Spence, R. J. S., Kelman, I., Calogero, E., Toyos, G., Baxter, P. J. and Komorowski, J.-C.: Modelling expected physical impacts and human casualties from explosive volcanic eruptions, Nat. Hazards Earth Syst. Sci., 5, 1003-1015, 2005 b.

Todesco, M., Neri, A., Esposti Ongaro, T., Papale, P., Macedonio, G., Santacroce, R., and Longo, A.: Pyroclastic flow hazard assessment at Vesuvius (Italy) by using numerical modeling. I. Large-scale dynamics, B. Volcanol., 64, 155-177, 2002.

Unanwa, C. O. and McDonald, J. R.: Statistical Analysis of Tornado-Generated Wood Missiles, 8th ASCE Speciality Conference on Probabilistic Mechanics and Structural reliability, University of Notre Dame, Indiana, USA, 2000.

Wills, J., Wyatt, T., and Lee, B.: Warnings of High Winds in Densely Populated Areas, Book 4 of the IDNDR Flagship Programme - Forecasts and Warnings, Thomas Telford, London, 1998.

Zuccaro, G. and Ianniello, D.: Interaction of pyroclastic flows with building structures in an urban settlement: a fluid-dynamic simulation impact model, J. Volcanol., 133, 345-352, 2004. 